\title{
In response to: tracheal tube stylets as a habit
}

\author{
Patrick Schoettker ${ }^{1} \cdot$ Sina Grape ${ }^{2}$
}

Received: 26 December 2016 / Accepted: 5 January 2017 / Published online: 30 January 2017

(C) Springer Science+Business Media Dordrecht 2017

To the editor, Thank you very much for your interest in our article "The role of tracheal tube introducers and stylets in current airway management" [1].

Management of difficult airway and endotracheal intubation have considerably changed with the routine use of optical and video-technologies. Modern optical and highresolution cameras allow better visualization of the anatomy, the laryngeal inlet as well as tracheal tube passage but mandate specific modifications in the handling of each new device used to assist tracheal intubation.

We agree with your comments about excessive routine use of stylets to assist intubation in the first place. However, guidelines in several countries recommend the use of stylets for specific emergency situations, such as pre-hospital or rapid-sequence intubations with a direct laryngoscope $[2,3]$.

The increasing use of video-laryngoscopic techniques in the clinical settings will however promote stylet or bougieassisted intubation techniques, even for routine situations. In these cases, stylets will not be used solely to "stiffen" the tracheal tube, but merely to pre-form it, according to patient's anatomy or the type of blade used, and to allow a more precise guidance of endo-tracheal tube movement [4]. Bougie-assisted intubation, on the other hand, may further allow "tube-railroading" with simultaneous video-laryngoscopy in difficult airway situation.

Patrick Schoettker

Patrick.Schoettker@chuv.ch

1 Department of Anesthesiology, University Hospital Center, University of Lausanne, Rue du Bugnon 46, 1011 Lausanne, Switzerland

2 Department of Anesthesiology, Hôpital de Sion, CH-1950 Sion, Switzerland
Profound understanding of video-laryngoscopic equipment used for intubation, especially type of blade (with or without a guiding channel, extremity angulation), will further increase the rate of success of difficult intubation. In some specific situations, depending on anatomy, equipment used and available resources, routine use of stylet or bougie might even be increasing.

\section{References}

1. Grape S, Schoettker P. The role of tracheal tube introducers and stylets in current airway management. J Clin Monit Comput. 2016. doi:10.1007/s10877-016-9879-8.

2. Rohsbach C, Wirth S, Lenz K, Priebe H. Survey on the current management of rapid sequence induction in Germany. Minerva Anestesiol. 2013;79(7):716-26.

3. Ridgway S, Hodzovic I, Woollard M, Latto IP. Prehospital airway management in Ambulance services in the United Kingdom. Anaesthesia. 2004;59(11):1091-4. doi:10.1111/j.1365-2044.2004.03965.x.

4. Schoettker P. The orotracheal tube dance. Eur J Anaesthesiol. 2015;32(6):443-4. doi:10.1097/EJA.0000000000000134. 